\title{
A Statistical Approach to Control Porosity in Silica-Doped Alumina Supports
}

Maryam Khosravi Mardkhe ${ }^{1}$, John Lawson², Baiyu Huang' ${ }^{1}$ Erika D. Handly ${ }^{1}$, and Brian F.

\author{
Woodfield ${ }^{1 *}$ \\ ${ }^{1}$ Department of Chemistry and Biochemistry, Brigham Young University, Provo, UT \\ 2Department. of Statistics, Brigham Young University, Provo, UT \\ *Brian_woodfield@byu.edu
}

\begin{abstract}
A split-plot statistical design was used to identify and systematically study the effects of synthesis variables on the pore properties of silica-doped alumina (SDA) from data obtained for 96 samples. Seven preparation variables (mixing method, time, environment; calcination ramp rate; drying temperature, environment; and alcohol concentration) were found to alter surface area, pore volume, and pore diameter over wide ranges, i.e. factors of $1.8,1.4$, and 3.3 , respectively. Large pore diameters $(>40 \mathrm{~nm})$ were obtained by addition of excess alcohol. Large pore volumes $\left(>2 \mathrm{~cm}^{3} / \mathrm{g}\right)$ were obtained by drying before calcination at $100^{\circ} \mathrm{C}$ for $24 \mathrm{~h}$. High surface area $\left(>400 \mathrm{~m}^{2} / \mathrm{g}\right)$ was obtained when no alcohol was used. The gamma phase of all SDA samples was thermally stable to $1200^{\circ} \mathrm{C}$. Using split-plot statistical analysis of the experimental data, models were developed which predict quantitatively the relationship between surface properties (surface area, pore volume and pore diameters) and synthesis parameters. Based on these models, optimal conditions to produce SDA samples with large (40-60 nm) or medium (16$19 \mathrm{~nm})$ pore diameters, high surface area $\left(>250 \mathrm{~m}^{2} / \mathrm{g}\right)$ and large pore volume $\left(>1 \mathrm{~cm}^{3} / \mathrm{g}\right)$ are quantitatively predicted. Model predictions of optimal conditions were accurately


confirmed by follow-up experiments. The chemistry underlying these predictions is also addressed.

Keywords: Control porosity, Split-plot design, Silica-doped alumina, Thermal stability.

\section{Introduction}

It is known that the performance of a catalyst strongly depends on the combination of textural, chemical and physical properties of the support. Among these properties, pore properties are critical for the successful design and optimization of a catalyst. Pore size is essential since each catalytic system requires a unique pore size for optimal catalyst loading, diffusion and selectivity [1-4]. Examples of this are in (1) Pt, Rh and Pd catalysts for automobile emission control (pore size 3 to $5 \mathrm{~nm}$ ) [5-8]; (2) Co(Ni)-Mo(W) sulfide catalysts for fuel hydrodesulfurization (pore size $>20 \mathrm{~nm}$ ) [8]; and (3) Co and Fe catalyst for Fischer-Tropsch synthesis (FTS) (pore size 10 to $20 \mathrm{~nm}$ ) [4, 9]. In addition, high surface area and large pore volume usually result in higher catalyst loading, which increases the number of catalytic reaction sites and decreases reaction time. Moreover, it is important to produce supports with good thermal stability since pore collapsing due to sintering at high temperatures often results in catalyst deactivation [10-15].

It has been reported previously that the pore properties of alumina catalyst supports are significantly influenced by a number of synthesis parameters, including the choice of aluminum source, synthesis route, structure directing agent, and solvent [16-22]. For example, Du et al. [16] synthesized alumina with pore diameters from 2-20 nm using sodium aluminate. Alumina having pore diameters from 4 to $8 \mathrm{~nm}$ have been prepared 
using nonionic polyethylene oxide-based surfactants [17], CTAB (Cetyltrimethylammonium bromide), carboxylic acid, and stearic acid surfactants [18-20], but poor thermal stability at high temperatures is reported. Zhang et al. [21] further enlarged the pore size range from 3.5 to $15 \mathrm{~nm}$ using TPAOH (tetrapropylammonium hydroxide), $\mathrm{CTAB}$, and $\mathrm{NaOH}$. Recently, Huang et al. [23] reported control of pore properties without using templates or surfactants. In their study, alumina having pore diameters from 4 to $18 \mathrm{~nm}$ are obtained by varying the water to aluminum molar ratio in the hydrolysis of aluminum alkoxides [23], and the pore size range is further extended from 4 to $37 \mathrm{~nm}$ by changing the alcohol used during the gelation [24]. In addition, it is well known that drying and calcination conditions are critical to the pore properties of alumina, since the former affects the formation of alumina precursors [25-28] and the latter induces the removal of surface hydroxyl groups, crystallization and sintering $[26,29,30]$.

Recently, we reported a facile solvent-deficient one-pot method to produce a high surface area and large pore volume $\gamma-\mathrm{Al}_{2} \mathrm{O}_{3}$ that is thermally stable up to $1200^{\circ} \mathrm{C}$ without transformation to $\alpha-\mathrm{Al}_{2} \mathrm{O}_{3}[31,32]$. These synthesized aluminas are not well-organized alumina [22] and do not have aligned channels of pores that discussed in previous papers $[33,34]$. However, the synthesized aluminas in this paper belong to less ordered alumina category, and pores are made of interstice between particles and agglomerate [23, 24, 35]. One of the application of the less ordered alumina is in FTS process as a catalyst support [35], and significant enhanced catalytic performances were observed on the catalyst using less ordered silica doped alumina. In this paper, the control of pore sizes, with large (40-60 $\mathrm{nm}$ ) or medium (16-19 nm) pore diameters of thermally stable $\gamma-\mathrm{Al}_{2} \mathrm{O}_{3}$, is achieved by 
controlling a number of synthesis factors, including mixing method, time, environment; calcination ramp rate; and alcohol concentration.

Since the pore properties are influenced by a large number of factors, it is important to understand the relationship between pore properties and each synthesis parameter; however, this requires significant time and cost to conduct all possible experiments to elucidate the effect of each variable. In this paper we will show that through the use of a statistical design, the important relationships can be determined at a fraction of the experimental cost and time.

Split-plot factorial statistical designs [36, 37] are useful when a randomized run order is structurally impossible, expensive, or inconvenient. Statistical reasons have been provided by Anbari et al. [38] to prefer a split-plot arrangement over a completely randomized design in these situations. They have shown that a smaller prediction variance can be achieved in some split-plot arrangements of two-level factorial designs than can be achieved with the corresponding completely randomized designs. Therefore, split-plot designs are more efficient when one or more of the factors need larger experimental units than other factors, or it is harder to change the levels of one or more of the factors [36]. In the synthesis of silica doped aluminas, a full factorial split-plot experimental design was useful because factors in the mixing process (mixing method, time, environment; and alcohol concentration) could only be varied between batches of reagents, while factors in the drying and calcination steps could be varied between portions of a single batch.

In this paper we used a split-plot fractional-factorial experimental design to obtain a useful mathematical model for the control of textural properties with a reduced cost and number of experiments $[39,40]$. Statistical analysis of the data from the experiments 
identified the most significant factors and interactions that affect on the pore diameter, surface area and pore volume of the resulting SDAs. The models obtained were then used to predict the ideal conditions necessary to produce high surface area, large pore volume, and differing pore sizes in the synthesis process.

\section{Experimental}

\subsection{Material}

The aluminum isopropoxide $\left(\mathrm{C}_{9} \mathrm{H}_{21} \mathrm{O}_{3} \mathrm{Al}\right)$ (granular, 98+\%) and the tetraethyl orthosilicate $\left(\mathrm{SiC}_{8} \mathrm{H}_{20} \mathrm{O}_{4}\right)$ (liquid, 99.9\%) (TEOS) were purchased from Alfa-Aeser. Distilled water was used throughout the synthesis.

\subsection{Synthesis method}

Silica-doped aluminas (100 g batches) were prepared by adding aluminum isopropoxide (AIP) and water in a 5:1 water to AIP mole ratio, $5 \mathrm{wt} . \%$ silica from tetraethyl orthosilicate (TEOS), and more water in a 2:1 water to TEOS mole ratio. The mixture was then mixed and thermally treated at $700^{\circ} \mathrm{C}$ in air for $2 \mathrm{~h}$ with a $5 \mathrm{~h}$ ramp rate. To measure thermal stability, samples were calcined to $1200^{\circ} \mathrm{C}$ in air for $2 \mathrm{~h}$ with a $5 \mathrm{~h}$ ramp rate.

The factors that were chosen to be varied in the split-plot factorial design were: (1) a sealed mixing environment (yes or no), (2) mixing method (hand or mechanical mixing), (3) alcohol concentration (yes or no), (4) drying precursor temperature $\left(25^{\circ} \mathrm{C}\right.$ or $100^{\circ} \mathrm{C}$ ), time (no or $24 \mathrm{~h}$ ), a sealed drying environment (yes or no), (5) calcination ramp $\left(1^{\circ} \mathrm{C} / \mathrm{min}\right.$ or $10^{\circ} \mathrm{C} / \mathrm{min}$ ). Mechanical mixing was carried out using a Bosch Universal mixer (model: MUM6N10UC). The total number of experiments were 96.

\subsection{Statistical analysis}


The specific design that we used is called a split-plot design with a full $2^{4}$ factorial in the whole plots, and a $3 / 4$ fraction of a $4 \times 2$ factorial design in the subplots. The analysis of the un-replicated split-plot experiment was made in two steps. Following the procedure described by Bisgaard [41], the whole plot means were analyzed in the first step to find which whole-plot factors and interactions were significant. This was done by calculating all effects and interactions in the saturated model for the $2^{4}$ design in the whole plots, and then identifying significant effects using a half-normal plot. After eliminating the insignificant whole plot effects and interactions, the second step was performed by fitting a mixed model to the individual observations [42]. The batch was considered to be a random factor, and the model was fit using the REML method with JMP 10 software. The JMP Fit Model menu was used to test all fixed effects in the model.

\subsection{Characterization}

The prepared silica-doped alumina samples were analyzed by powder x-ray diffraction (XRD) using a PANalytical X'Pert Pro diffractrometer with a Cu Ka x-ray source $(\lambda=1.5418 \AA ̊ \Omega)$ operated at $45 \mathrm{kV}$ and $40 \mathrm{~mA}$. Scans were performed between $10^{\circ}$ and $90^{\circ}$ $2 \theta$ with a step size of $0.0167^{\circ}$ at a rate of $0.013^{\circ} \mathrm{s}^{-1}$.

Nitrogen adsorption measurements were carried out using a Micromerictics Tristar 3020 for the determination of surface properties at $-196^{\circ} \mathrm{C}$. Surface area was calculated using the Brunauner-Emmett-Teller (BET) model in the $\mathrm{P} / \mathrm{P}_{0}$ range from 0.05 to 0.20 . Pore volumes were determined at a single point of $\mathrm{P} / \mathrm{P}_{0}$ equal to 0.990 . Pore size distributions were calculated using an improved slit pore geometry (SPG) model for large pore sizes [43]. Samples were degassed at $200^{\circ} \mathrm{C}$ under $\mathrm{N}_{2}$ flow overnight before every measurement. 
Microscopic image of sample of batch two with no drying condition (Table 1) was obtained with an FEI Philips Tecani F30 transmission electron microscope (TEM) at a voltage of $200 \mathrm{kV}$. TEM sample was prepared by placing a drop of silica-doped alumina ( $1 \%$ dispersed in ethanol) on a carbon film with a copper mesh grid (Ted-Pella Inc.).

\section{Results}

\subsection{Synthesis}

Table 1 shows the list of experiments for the un-replicated split-plot design experiments to produce the silica-doped alumina (SDA) catalyst supports. It shows that all synthesized SDAs are mostly in gamma or theta phases at $1200^{\circ} \mathrm{C}$ (based on XRD data) suggesting high thermal stability. Figure 1 shows that all isotherms are Type IV, indicating synthesized aluminas pores are mesoporous. $[4,24,44]$

\subsection{Statistical model}

The statistical prediction equations determined from the data analysis for surface area, pore volume, and pore diameters are shown in Equations 1- 3 below.

$$
\begin{gathered}
S A_{i j k l m}=\mu+A_{i}+M_{j}+w_{(i j) k}+D_{l}+C_{m}+A M_{i j}+A D_{i l}+A C_{i m}+D C_{l m}+ \\
A M D_{i j l}+A M C_{j m l}+\varepsilon_{i j k l m}
\end{gathered}
$$

where $S A_{i j k l m}$ is the surface area in the $k$ th batch, prepared using the $i$ th level of excess alcohol and the $j$ th level of mixture method, the lth level of drying method and the $m$ th level of calcination ramp. $A_{i}$ is the fixed main effect of the excess alcohol, $M_{j}$ is the fixed main effect of the mixing method, and $w_{(i j) k}$ is the random effect of the $k$ th batch nested in the 
combination of excess alcohol and mixing method. $D_{l}$ is the fixed main effect of drying method, $C_{m}$ is the fixed main effect of the calcination ramp, $\varepsilon_{i j k l m}$ is the random subplot error term, and the other terms in the model are interactions among the main effects.

$$
P V_{i j k}=\mu+M_{i}+w_{(i) j}+D_{k}+\varepsilon_{i j k}
$$

where $P V_{i j k}$ is the pore volume in the $j$ th batch prepared using the $i$ th level of excess alcohol, and the $k$ th level of drying method. $M_{i}$ is the fixed main effect of mixing method, $D_{k}$ is the fixed main effect of drying method, and $\varepsilon_{i j k}$ is the random subplot error term.

$$
P D_{i j k l m}=\mu+A_{i}+M_{j}+S_{k}+T_{l}+S T_{k l}+M S_{j k}+M T_{j l}+A M S T_{i j k l}+w_{i j k l m}
$$

where $P D_{i j k l m}$ is the large pore diameter in the $m$ th batch prepared using the $i$ th level of excess alcohol, the $j$ th level of mixing method, the $k$ th level of mixing seal, and the lth level of mixing time. $A_{i}$ is the fixed main effect of excess alcohol, $M_{j}$ is the fixed main effect of mixing method, $S_{k}$ is the fixed main effect of mixing seal, $T_{l}$ is the fixed main effect of mixing time, $w_{i j k l m}$ is the random batch effect, and the other terms in the model are interactions among the main effects

\subsection{Influences of factors}

\subsubsection{Surface Area}


Figure 2 shows that the excess alcohol usage has the largest effect on the surface area. On average, adding excess alcohol decreases surface area by $72 \mathrm{~m}^{2} / \mathrm{g}$. In addition, due to the significant interaction between excess alcohol, drying method, and mixing method, the change in surface area caused by adding excess alcohol depends on both the mixing method and the drying method. Also, due to the interaction between adding excess alcohol and the calcination ramp, the change in surface area caused by adding excess alcohol is slightly different depending on the calcination ramp.

It is shown in Figure 2 that adding alcohol causes a decrease in surface area in most situations. However, when the batch is hand mixed and dried for $24 \mathrm{~h}$ at $100^{\circ} \mathrm{C}$ without sealing the drying environment, adding alcohol increases surface area from $368 \mathrm{~m}^{2} / \mathrm{g}$ to $407 \mathrm{~m}^{2} / \mathrm{g}$. Also, when the batch was mixed by machine and dried for $24 \mathrm{~h}$ at $100^{\circ} \mathrm{C}$ without sealing the drying environment, adding alcohol has very little effect on the surface area. On average the effect of adding alcohol reduces surface area when the batch was mixed by machine rather than by hand.

Figure 3 illustrates the dependency between the effect of excess alcohol and the calcination ramp. When the calcination ramp is $10^{\circ} \mathrm{C} / \mathrm{min}$., adding excess alcohol decreases surface area by $91 \mathrm{~m}^{2} / \mathrm{g}$. However, when the calcination ramp is reduced to $1^{\circ} \mathrm{C} / \mathrm{min}$. adding excess alcohol only decreases the surface area by $52 \mathrm{~m}^{2} / \mathrm{g}$. Figure 2 also shows that the effect of drying method on surface area depends on both the mixing method and whether excess alcohol is added. This is again due to the significant interaction between excess alcohol, drying method and mixing method.

\subsubsection{Pore diameter}


Figure 4 shows that, on average, adding excess alcohol increases the pore diameter by $18.6 \mathrm{~nm}$. However, due to the significant interactions, the change in pore diameter caused by adding excess alcohol is much greater or less than $18.6 \mathrm{~nm}$ depending on the mixing method used and whether a sealed mixing environment was used. In the left panel (Figure 4) where no sealed mixing environment is used and the batch is mixed by hand, adding excess alcohol increases pore diameter by about $25 \mathrm{~nm}$ regardless of the mixing time. On the other hand, when a sealed mixing environment is used and the batch is mixed by hand for 30 minutes, adding excess alcohol only increases the large pore diameter by about $5 \mathrm{~nm}$. The change in pore diameter caused by adding excess alcohol for all 8 combinations of sealed mixing environment, mixing method and mixing time is visualized as the vertical differences in the ends of the lines in Figure 4.

\subsubsection{Pore volume}

As seen in Figure 5, drying method has the most significant effect on pore volume, where drying at $100^{\circ} \mathrm{C}$ in an unsealed drying environment for $24 \mathrm{~h}$ produces the largest pore volume. No drying condition produces the smallest pore volume, and there is little difference in pore volume between the other two drying conditions at $25^{\circ} \mathrm{C}$. Switching from hand mixing to machine mixing decreases pore volume on the average by $0.157 \mathrm{~cm}^{2} / \mathrm{g}$ (see Figure 6).

\section{Discussion}

\subsection{Confirmation of Model Predictions}

Equations 1-3 and Figures 2-6 were used to identify seven different optimal synthesis conditions that were predicted to produce SDA with large or medium pore diameters, simultaneously with a large surface area and pore volume. The seven optimal 
conditions were combinations of the levels or alternatives for mixing method, environment, and time; alcohol concentration; and the drying method. Table 2 shows these seven optimal conditions along with the predicted surface area, pore volume and large pore diameter at each condition. Confirmation experiments were run where a single batch of SDA was synthesized at each of the conditions listed in Table 2. The surface area, pore volume and large pore diameter for each of these batches was measured and are shown in the last three columns of Table 2. The results of six confirmation experiments agree with the model and graphical predictions except for experiment 3. However, experiment 3 is not reliable since using mechanical mixing in an unsealed environment for 30 minutes dries the mixture and the mixture spills over the bowl. The six experiments in agreement with the model predictions show that the statistical analysis has indeed identified the important synthesis factors that control the surface area, pore volume, and large pore diameter of SDA. In addition it has been demonstrated that batches of SDA can be produced with high surface areas, large pore volumes, and large (40-60 nm) or medium (16-19 nm) pore diameters.

\subsection{The effect of excess alcohol}

The results from the statistical analysis show that using alcohol in the mixing step has a negative effect on surface area and a positive influence on the pore diameter of SDAs (Figures 2 and 4), which is supported by the chemistry involved in the synthesis. Baker [45] suggested that the formation of an alumina precursor can be viewed as a polymerization of $\mathrm{Al}\left(\mathrm{H}_{2} \mathrm{O}\right)_{6}{ }^{3+}$ octahedrals. When the hydrolysis rate is slow, this polymerization occurs in three dimensions rather than one dimension under fast hydrolysis conditions. This is confirmed by the TEM images of the SDAs. As shown in Figure 
7, the primary particles of SDAs are slab like under slow hydrolysis condition, consistent with Baker's and Huang's results $[23,45]$. Since there are a significant number of hydroxyl groups on the surfaces of the alumina precursor, excess alcohol is adsorbed on the surface planes of the bohemite crystallite (alumina precursor) via hydrogen bonding. This reduces the surface energy of the alumina precursor and inhibits the polymerization of the primary crystallites [46-48]. In addition, excess alcohol enhances the mobility of the alumina precursor and avoids pile stacking of the alumina plates. When the alcohol evaporates, an open 3D-stacking structure (or "house of cards") consisting of the alumina plates is formed and large pore diameters are observed, consistent with the results of previous studies [18, 24, 49-52]. In addition, when excess alcohol is used in combination with sealing the Bosch mixer and increasing the mixing, the pore diameter increases further, since sealing limits alcohol evaporation and helps maintain an alcohol rich environment and increased mixing enables the completion of the hydrolysis reaction and hydrogen bonding formation. Note that larger pore diameters are often observed with lower surface area [14, 15, 23, 24, 53].

\subsection{The effect of excess alcohol and calcination ramp rate}

As mentioned in section 4.1, adding excess alcohol decreases the surface area. In the case of a high calcination ramp rate, the surface area decreases by $91 \mathrm{~m}^{2} / \mathrm{g}$; however, when the calcination ramp rate is slow, the surface area decreases by $52 \mathrm{~m}^{2} / \mathrm{g}$ (Figure 3). A slow calcination ramp rate results in slow shrinkage and formation of the isolated small particles [54]. The isolated particles have a lower tendency to bond to adjacent particles enabling them to grow into larger particles. A slow calcination ramp rate also provides sufficient time for both the interlayer hydroxyls and extra solvent to be removed without damaging the structure [24]. 


\subsection{Effect of drying}

From the statistical results, it is evident that drying affects the pore volume and surface area of SDAs. Pore volume and surface area increase with drying of the precursor compared to no control of the drying conditions, especially at higher temperature $\left(100^{\circ} \mathrm{C}\right)$ (Figures. 2, 5). Drying leads to formation of further M-O-M cross-links in the gel as covalent linkages replace weak interactions between surface hydroxyl and alkoxy groups. This allows neighboring $\mathrm{M}-\mathrm{OH}$ or $\mathrm{M}-\mathrm{OR}$ groups to approach each other and undergo a condensation reaction [54] resulting in larger pore volumes. Solvent evaporation in the drying step produces a capillary pressure due to the difference between the solid-vapor and solid-liquid interfacial energies [54]. When the capillary pressure increases, liquid moves to smaller interstices (pores) with the greatest surface to volume ratio. As a result primary particles rearrange themselves during the drying process to form pores with similar sizes [53]. Since the solvent is slowly evaporated when the precursor is dried at low temperature $\left(25^{\circ} \mathrm{C}\right)$, there is enough time for this rearrangement process to finish [55] and a smaller pore volume is observed. In contrast, when drying occurs at higher temperatures $\left(100^{\circ} \mathrm{C}\right)$, the solvent is removed much faster and the rearrangement is not completed resulting in a larger pore volume. Maintaining drying conditions at $25^{\circ} \mathrm{C}$ with a sealed environment for $24 \mathrm{~h}$ resulted in a higher surface area and larger pore volume than the unsealed drying environment, suggesting more cross linking and reduced pile stacking of plates due to slower alcohol evaporation.

\section{Conclusion}


The synthesis of thermally stable silica-doped alumina (SDA) catalyst supports has been studied using a split-plot full fractional factorial design. From this study, the following conclusions can be drawn:

1. It was found that mixing method, time, and environment; calcination ramp rate; drying temperature and environment; and alcohol concentration can alter surface area, pore volume, and pore diameter by factors of $1.8,1.4$, and 3.3 , respectively. Large pore diameters $(>40 \mathrm{~nm})$, large pore volumes $\left(>2 \mathrm{~cm}^{3} / \mathrm{g}\right)$, and high surface area $\left(>400 \mathrm{~m}^{2} / \mathrm{g}\right)$ were obtained by addition of excess alcohol, drying at $100^{\circ} \mathrm{C}$ for $24 \mathrm{~h}$, and no alcohol usage, respectively.

2. The proposed quantitative models can predict optimal conditions to produce SDAs with high surface areas $\left(>250 \mathrm{~m}^{2} / \mathrm{g}\right)$, large pore volume $\left(>1 \mathrm{~cm}^{3} / \mathrm{g}\right)$, and large (40$60 \mathrm{~nm})$ or medium $(16-19 \mathrm{~nm})$ pore diameters.

\section{Acknowledgments}

This work was supported by the U.S. Department of Energy under grant DE-FG0205ER15666 and National Science Foundation under CHE-0959862. 


\section{References}

[1] J. Cejka, Appl. Catal., A, 254 (2003) 327-338.

[2] C. Morterra, G. Magnacca, Catal. Today, 27 (1996) 497-532.

[3] R.K. Oberlander, Appl. Ind. Catal., 3 (1984) 63-112.

[4] C.H. Bartholomew, R.J. Farrauto, Fundumental of industrial catalytic processes, 2 ed., John Wiley and sons Inc., 2006.

[5] K.C. Taylor, Catal. Rev. Sci. Eng., 35 (1993) 457-481.

[6] D.N. Belton, K.C. Taylor, Curr. Opin. Solid State Mater. Sci., 4 (1999) 97-102.

[7] M. Ozawa, J. Alloys Compd., 408-412 (2006) 1090-1095.

[8] O.V. Klimov, M.A. Fedotov, A.V. Pashigreva, S.V. Budukva, E.N. Kirichenko, G.A. Bukhtiyarova, A.S. Noskov, Kinet. Catal., 50 (2009) 867-873.

[9] A.D.L. A. R. de la Osa, A. Romero, J.L.valverde, P. Sanchez, Catal. Today, 176 (2011) 298302.

[10] J.W. Curley, M.J. Dreelan, O.E. Finlayson, Catal. Today, 10 (1991) 401-404.

[11] T. Fukui, M. Hori, J. Mater. Sci., 30 (1995) 1794-1800.

[12] T. Horiuchi, T. Osaki, T. Sugiyama, H. Masuda, M. Horio, K. Suzuki, T. Mori, T. Sago, J. Chem. Soc., Faraday Trans., 90 (1994) 2573-2578.

[13] J.B. Miller, E.I. Ko, Catal. Today, 43 (1998) 51-67.

[14] A.A. Shutilov, G.A. Zenkovets, S.V. Tsybulya, V.Y. Gavrilov, Kinet. Catal., 53 (2012) 125136.

[15] T. Horiuchi, L. Chen, T. Osaki, T. Sugiyama, K. Suzuki, T. Mori, Catal. Lett., 58 (1999) 8992.

[16] T.-B. Du, S.-M. Jang, B.-W. Chen, Chem. Eng. Sci., 62 (2007) 4864-4868.

[17] S.A. Bagshaw, T.J. Pinnavaia, Angew. Chem., Int. Ed. Engl., 35 (1996) 1102-1105.

[18] W. Deng, M.W. Toepke, B.H. Shanks, Adv. Funct. Mater., 13 (2003) 61-65.

[19] F. Vaudry, S. Khodabandeh, M.E. Davis, Chem. Mater., 8 (1996) 1451-1464.

[20] Y. Kim, C. Kim, P. Kim, J. Yi, J. Non-Cryst. Solids, 351 (2005) 550-556.

[21] Z. Zhang, T.J. Pinnavaia, Langmuir, 26 (2010) 10063-10067. 
[22] C. Márquez-Alvarez, N. Žilková, J. Pérez-Pariente, J. ejka, Catal. Rev. Sci. Eng., 50 (2008) 222-286.

[23] B. Huang, C.H. Bartholomew, S.J. Smith, B.F. Woodfield, Micropor. Mesopor. Mater., 165 (2013) 70-78.

[24] B. Huang, C.H. Bartholomew, B.F. Woodfield, Micropor. Mesopor. Mater., 177 (2013) $37-46$.

[25] M. Jafarzadeh, I.A. Rahman, C.S. Sipaut, J. Sol-Gel Sci. Technol., 50 (2009) 328-336.

[26] R.F. Silva, W.L. Vasconcelos, Mater. Res. (Sao Carlos, Braz.), 2 (1999) 197-200.

[27] E. Ponthieu, E. Payen, G.M. Pajonk, J. Grimblot, J. Sol-Gel Sci. Technol., 8 (1997) 201206.

[28] J. Cejka, P.J. Kooyman, L. Vesela, J. Rathouskya, A. Zukala, Phys. Chem. Chem. Phys., 4 (2002) 4823-4829.

[29] J. Nair, P. Nair, J.G. Van Ommen, J.R.H. Ross, A.J. Burggraaf, J. Am. Ceram. Soc., 81 (1998) 1487-1492.

[30] G. Urretavizcaya, A.L. Cavalieri, J.M.P. Lopez, I. Sobrados, J. Sanz, J. Mater. Synth. Process., 6 (1998) 1-7.

[31] M.K. Mardkhe, B.F. Woodfield, C.H. Bartholomew, A method of producing thermally stable and high surface area $\mathrm{Al}_{2} \mathrm{O}_{3}$ catalyst supports, in, Brigham Young University, USA, 2013.

[32] M.K. Mardkhe, B. Huang, C. Bratholomew, T.M. Alam, B. F. Woodfield, Micropor. Mesopor. Mater. (2014) Submitted.

[33] Q. Wu, F. Zhang, J. Yang, Q. Li, B. Tu, D. Zhao, Micropor. Mesopor. Mater., 143 (2011) 406-412.

[34] D. Pan, M. Guo, M. He, S. Chen, X. Wang, F. Yu, R. Lia, J. Mater. Res., 29 (2014) 811-819.

[35] K. Keyvanloo, M. Khosravi-Mardkhe, T.M. Alam, C.H. Bartholomew, B.F. Woodfield, W.C. Hecker, ACS Catalysis, 4 (2014) 1071-1077.

[36] B. Jones, J. Qual. Tech., 41 (2009) 340-361.

[37] R.A. Fisher, statistical methods for research workers, Oliver and Boyd, 1925.

[38] F.T. Anbari, J.M. Lucas, technical conference transactions, (1994) 852-863.

[39] M. Martinez, J. Aracil, Ing. Quim. (Madrid), 21 (1989) 163-168. 
[40] G. Box, J. hunter, statistics for experimenter, John Wiley and sons, New York, 1978.

[41] S. Bisgard, H.T. Fuller, E. Barrios, Quality Engineering, 8 (1996) 705-708.

[42] J. Lawson, Design and Analysis of Experiments with SAS, in, CRC Press, Boca Raton, 2010.

[43] B. Huang, C.H. Bartholomew, B.F. Woodfield, Micropor. Mesopor. Mater. 184 (2014) 112-121.

[44] J. Cejka, N. Zilkova, J. Rathousky, A. Zukal, Phys. Chem. Chem. Phys., 3 (2001) 50765081.

[45] B.R. Baker, R.M. Pearson, J. Catal., 33 (1974) 265-278.

[46] A. Mueller, O. Heim, M. Panneerselvam, M. Willert-Porada, Mater. Res. Bull., 40 (2005) 2153-2169.

[47] R. Bleta, P. Alphonse, L. Pin, M. Gressier, M.-J. Menu, J. Colloid Interface Sci., 367 (2011) 120-128.

[48] S.M. Grant, M. Jaroniec, J. Colloid Interface Sci., 367 (2012) 129-134.

[49] R.W. Hicks, T.J. Pinnavaia, Chem. Mater., 15 (2003) 78-82.

[50] J.-L. Blin, A. Leonard, Z.-Y. Yuan, L. Gigot, A. Vantomme, A.K. Cheetham, B.-L. Su, Angew. Chem., Int. Ed., 42 (2003) 2872-2875.

[51] A. Leonard, J.-L. Blin, B.-L. Su, Chem. Commun. (Cambridge, U. K.), (2003) 2568-2569.

[52] B. Cormack, J.J. Freeman, K.S.W. Sing, J. Chem. Technol. Biotechnol., 30 (1980) 367-373.

[53] N. Yao, G. Xiong, M. He, S. Sheng, W. Yang, X. Bao, Chem. Mater., 14 (2002) 122-129.

[54] U. Schubert, N. Husing, Synthesis of Inorganic Material, in, Wiley-VCH verlang GmbH, 2000.

[55] J.D. Wright, N.A.J.M. Sommerdijk, Sol-Gel Materials Chemistry and Application, in, Gordon and Breach Science Publisher, 2001. 


\section{$\underline{\text { Tables }}$}

Table 1. Experiments to make silica-doped aluminas (SDA)

\begin{tabular}{|c|c|c|c|c|c|c|c|c|c|c|c|}
\hline Batch & $\begin{array}{l}\text { Surface } \\
\text { area } \\
\left(\mathrm{m}^{2} / g\right)^{a}\end{array}$ & $\begin{array}{l}\text { Pore } \\
\text { volume } \\
\left(\mathrm{cm}^{2} / \mathrm{g}\right)^{\mathrm{a}}\end{array}$ & $\begin{array}{l}\text { Pore } \\
\text { diameter } \\
(\mathrm{nm})^{\mathrm{b}}\end{array}$ & $\begin{array}{l}\text { St. } \\
\text { dev } \\
(\mathrm{nm})\end{array}$ & $\begin{array}{l}\text { Mixing } \\
\text { method } \\
\text { H:hand } \\
\text { M:Bosch }\end{array}$ & $\begin{array}{l}\text { Mixing } \\
\text { seal } \\
\text { Y:sealed } \\
\text { N: not } \\
\text { sealed }\end{array}$ & $\begin{array}{l}\text { Mixing } \\
\text { time } \\
\text { (min) } \\
\text { H:30 } \\
\text { L:15 }\end{array}$ & $\begin{array}{l}\text { Alcohol } \\
\text { Y:yes } \\
\text { N:no }\end{array}$ & $\begin{array}{l}\text { Drying: } \\
\text { N:no } \\
\text { Y:yes } \\
\left(\text { Time(h) } / \mathrm{T}\left({ }^{\circ} \mathrm{C}\right) /\right. \\
\text { cap(on or off) }\end{array}$ & $\begin{array}{l}\text { calcination } \\
\text { ramp } \\
\left({ }^{\circ} \mathrm{C} / \mathrm{min}\right)\end{array}$ & $\begin{array}{l}\text { Phase at } \\
\left(1200^{\circ} \mathrm{C}\right)^{\mathrm{c}}\end{array}$ \\
\hline 1 & 262 & 1.527 & 35.7 & 1.6 & \multirow{6}{*}{$\mathrm{H}$} & \multirow{6}{*}{ Y } & \multirow{6}{*}{$\mathrm{L}$} & \multirow{6}{*}{$\mathrm{Y}$} & $\mathrm{N}$ & 1 & $\gamma$ \\
\hline 1 & 233 & 1.431 & 37.7 & 1.6 & & & & & $\mathrm{~N}$ & 10 & $\gamma$ \\
\hline 1 & 353 & 2.124 & $21.4,58.4$ & $1.9,1.3$ & & & & & $24 \mathrm{~h} / 25^{\circ} \mathrm{C} /$ cap on & 1 & $\gamma+$ trace? \\
\hline 1 & 272 & 1.564 & 44.0 & 1.6 & & & & & $24 \mathrm{~h} / 25^{\circ} \mathrm{C} /$ cap on & 10 & $\gamma$ \\
\hline 1 & 269 & 1.524 & 44.2 & 1.6 & & & & & $24 \mathrm{~h} / 25^{\circ} \mathrm{C} /$ cap off & 1 & $\gamma$ \\
\hline 1 & 280 & 1.647 & 45.4 & 1.5 & & & & & $24 \mathrm{~h} / 25^{\circ} \mathrm{C} /$ cap off & 10 & $\gamma$ \\
\hline 2 & 312 & 1.689 & $18.8,60.4$ & $2.9,1.4$ & \multirow{6}{*}{ M } & \multirow{6}{*}{$\mathrm{Y}$} & \multirow{6}{*}{$\mathrm{H}$} & \multirow{6}{*}{$\mathrm{N}$} & $\mathrm{N}$ & 1 & $\gamma+\operatorname{trace} \alpha$ \\
\hline 2 & 342 & 1.667 & $18.7,50.1$ & $1.6,1.6$ & & & & & $\mathrm{~N}$ & 10 & $\gamma+\operatorname{trace} \alpha$ \\
\hline 2 & 367 & 1.948 & $15.9,49.3$ & $1.5,1.6$ & & & & & $24 \mathrm{~h} / 100^{\circ} \mathrm{C} / \mathrm{cap}$ off & 1 & $\gamma+\operatorname{trace} \alpha$ \\
\hline 2 & 393 & 2.134 & $16.1,49.4$ & $1.5,1.6$ & & & & & $24 \mathrm{~h} / 100^{\circ} \mathrm{C} /$ cap off & 10 & $\gamma+$ trace? \\
\hline 2 & 330 & 1.735 & $16.7,49.4$ & $1.6,1.6$ & & & & & $24 \mathrm{~h} / 25^{\circ} \mathrm{C} /$ cap on & 1 & $\gamma+\operatorname{trace} \alpha$ \\
\hline 2 & 320 & 1.542 & $19,51.3$ & $1.8,1.9$ & & & & & $24 \mathrm{~h} / 25^{\circ} \mathrm{C} /$ cap on & 10 & $\gamma+$ trace? \\
\hline 3 & 402 & 1.937 & 16.9 & 1.3 & \multirow{6}{*}{$\mathrm{H}$} & \multirow{6}{*}{$\mathrm{Y}$} & \multirow{6}{*}{$\mathrm{L}$} & \multirow{6}{*}{$\mathrm{N}$} & $\mathrm{N}$ & 1 & $\gamma+$ trace? \\
\hline 3 & 336 & 1.799 & 18.2 & 1.2 & & & & & $\mathrm{~N}$ & 10 & $\gamma+$ trace? \\
\hline 3 & 384 & 1.63 & 15.9 & 1.2 & & & & & $24 \mathrm{~h} / 100^{\circ} \mathrm{C} /$ cap off & 1 & $\gamma+$ trace? \\
\hline 3 & 434 & 2.128 & 16.4 & 1.4 & & & & & $24 \mathrm{~h} / 100^{\circ} \mathrm{C} / \mathrm{cap}$ off & 10 & $\gamma+$ trace? \\
\hline 3 & 447 & 2.194 & 15.5 & 1.4 & & & & & $24 \mathrm{~h} / 25^{\circ} \mathrm{C} /$ cap on & 1 & $\gamma+$ trace? \\
\hline 3 & 389 & 1.969 & 17.8 & 1.2 & & & & & $24 \mathrm{~h} / 25^{\circ} \mathrm{C} /$ cap on & 10 & $\gamma+$ trace? \\
\hline 4 & 345 & 1.768 & 17.2 & 1.3 & \multirow{6}{*}{ M } & \multirow{6}{*}{$\mathrm{N}$} & \multirow{6}{*}{$\mathrm{L}$} & \multirow{6}{*}{$\mathrm{N}$} & $\mathrm{N}$ & 1 & $\gamma+\operatorname{trace} \alpha$ \\
\hline 4 & 356 & 1.635 & 18.3 & 1.3 & & & & & $\mathrm{~N}$ & 10 & $\gamma+\operatorname{trace} \alpha$ \\
\hline 4 & 408 & 1.836 & 17.0 & 1.3 & & & & & $24 \mathrm{~h} / 25^{\circ} \mathrm{C} /$ cap on & 1 & $\gamma+\operatorname{trace} \alpha$ \\
\hline 4 & 386 & 1.888 & 17.5 & 1.3 & & & & & $24 \mathrm{~h} / 25^{\circ} \mathrm{C} /$ cap on & 10 & $\gamma+\operatorname{trace} \alpha$ \\
\hline 4 & 348 & 1.662 & 18.7 & 1.4 & & & & & $24 \mathrm{~h} / 25^{\circ} \mathrm{C} /$ cap off & 1 & $\gamma+\operatorname{trace} \alpha$ \\
\hline 4 & 340 & 1.719 & 18.7 & 1.3 & & & & & $24 \mathrm{~h} / 25^{\circ} \mathrm{C} /$ cap off & 10 & $\gamma+$ trace? \\
\hline 5 & 336 & 1.651 & $21.5,53.8$ & $2.1,1.6$ & \multirow{6}{*}{ M } & \multirow{6}{*}{$\mathrm{N}$} & \multirow{6}{*}{$\mathrm{L}$} & & $24 \mathrm{~h} / 25^{\circ} \mathrm{C} /$ cap on & 1 & $\gamma+\operatorname{trace} \alpha$ \\
\hline 5 & 285 & 1.56 & $22.4,60.2$ & $2.5,1.2$ & & & & & $24 \mathrm{~h} / 25^{\circ} \mathrm{C} /$ cap on & 10 & $\gamma+\operatorname{trace} \alpha$ \\
\hline 5 & 319 & 1.493 & 36.6 & 1.7 & & & & $\mathrm{~V}$ & $24 \mathrm{~h} / 25^{\circ} \mathrm{C} /$ cap off & 1 & $\gamma+\alpha$ \\
\hline 5 & 289 & 1.578 & $21,54.7$ & $2.0,1.6$ & & & & $Y$ & $24 \mathrm{~h} / 25^{\circ} \mathrm{C} /$ cap off & 10 & $\gamma+\alpha$ \\
\hline 5 & 408 & 2.245 & $17.8,47.9$ & $1.5,1.7$ & & & & & $24 \mathrm{~h} / 100^{\circ} \mathrm{C} / \mathrm{cap}$ off & 1 & $\gamma+\operatorname{trace} \alpha$ \\
\hline 5 & 382 & 2.264 & $18.6,49$ & $1.8,1.6$ & & & & & $24 \mathrm{~h} / 100^{\circ} \mathrm{C} /$ cap off & 10 & $\gamma+\operatorname{trace} \alpha$ \\
\hline 6 & 316 & 1.198 & $20.7,53.5$ & $2.3,1.5$ & & & & & $\mathrm{~N}$ & 1 & $\gamma$ \\
\hline 6 & 209 & 1.167 & $28.6,61.2$ & $3.2,0.9$ & & & & & $\mathrm{~N}$ & 10 & $\gamma$ \\
\hline 6 & 430 & 2.437 & $18,48.4$ & $1.6,1.7$ & $M$ & $\mathrm{~V}$ & I & $\mathrm{y}$ & $24 \mathrm{~h} / 100^{\circ} \mathrm{C} /$ cap off & 1 & $\gamma+\operatorname{trace} \alpha$ \\
\hline 6 & 320 & 1.815 & $22.2,58.8$ & $2.5,1.6$ & $\mathbf{M}$ & $Y$ & $\mathrm{~L}$ & $Y$ & $24 \mathrm{~h} / 100^{\circ} \mathrm{C} / \mathrm{cap}$ off & 10 & $\gamma$ \\
\hline 6 & 336 & 1.594 & $22.0,57.2$ & $2.2,1.5$ & & & & & $24 \mathrm{~h} / 25^{\circ} \mathrm{C} /$ cap on & 1 & $\gamma+$ trace? \\
\hline 6 & 310 & 1.786 & $21.1,50.5$ & $2.0,1.8$ & & & & & $24 \mathrm{~h} / 25^{\circ} \mathrm{C} /$ cap on & 10 & $\gamma$ \\
\hline 7 & 235 & 1.139 & $27.7,61.7$ & $3.5,1.0$ & & & & & $\mathrm{~N}$ & 1 & $\gamma$ \\
\hline 7 & 294 & 1.64 & $22.6,60.6$ & $3.4,0.9$ & & & & & $\mathrm{~N}$ & 10 & $\gamma+\alpha$ \\
\hline 7 & 388 & 2.364 & $20.0,57.5$ & $1.9,1.0$ & & & & & $24 \mathrm{~h} / 100^{\circ} \mathrm{C} / \mathrm{cap}$ off & 1 & $\gamma+$ trace? \\
\hline 7 & 378 & 2.284 & $19.4,48.8$ & $1.6,1.8$ & $\mathrm{M}$ & $Y$ & $\mathrm{H}$ & $Y$ & $24 \mathrm{~h} / 100^{\circ} \mathrm{C} / \mathrm{cap}$ off & 10 & $\gamma+$ trace? \\
\hline 7 & 242 & 1.275 & $23.5,59.5$ & $2.4,1.4$ & & & & & $24 \mathrm{~h} / 25^{\circ} \mathrm{C} /$ cap off & 1 & $\gamma$ \\
\hline 7 & 246 & 1.319 & $23.1,60$ & $2.8,1.4$ & & & & & $24 \mathrm{~h} / 25^{\circ} \mathrm{C} /$ cap off & 10 & $\gamma$ \\
\hline 8 & 368 & 1.681 & 16.6 & 1.27 & & & & & $24 \mathrm{~h} / 100^{\circ} \mathrm{C} /$ cap off & 1 & $\gamma+\operatorname{trace} \alpha$ \\
\hline 8 & 393 & 1.536 & 17.2 & 1.24 & & & & & $24 \mathrm{~h} / 100^{\circ} \mathrm{C} /$ cap off & 10 & $\gamma+\alpha$ \\
\hline 8 & 350 & 1.48 & 13.7 & 1.31 & $\mathrm{H}$ & $\mathrm{N}$ & $\mathrm{L}$ & $\mathrm{N}$ & $24 \mathrm{~h} / 25^{\circ} \mathrm{C} /$ cap on & 1 & $\gamma$ \\
\hline 8 & 367 & 1.922 & 17.2 & 1.23 & & & & & $24 \mathrm{~h} / 25^{\circ} \mathrm{C} /$ cap on & 10 & $\gamma+$ trace? \\
\hline 8 & 424 & 2.145 & 19.4 & 1.37 & & & & & $24 \mathrm{~h} / 25^{\circ} \mathrm{C} / \mathrm{cap}$ off & 1 & $\gamma+\operatorname{trace} \alpha$ \\
\hline
\end{tabular}




\begin{tabular}{|c|c|c|c|c|c|c|c|c|c|c|c|}
\hline 8 & 414 & 2.145 & 17.5 & 1.26 & & & & & $24 \mathrm{~h} / 25^{\circ} \mathrm{C} /$ cap off & 10 & $\gamma+\operatorname{trace} \alpha$ \\
\hline 9 & 340 & 1.721 & $16.8,48.4$ & $1.5,1.9$ & \multirow{6}{*}{$\mathrm{H}$} & \multirow{6}{*}{$\mathrm{Y}$} & \multirow{6}{*}{$\mathrm{H}$} & \multirow{6}{*}{$\mathrm{N}$} & $\mathrm{N}$ & 1 & $\gamma$ \\
\hline 9 & 356 & 1.643 & $15.6,45.4$ & $1.6,1.4$ & & & & & $\mathrm{~N}$ & 10 & $\gamma$ \\
\hline 9 & 315 & 1.74 & $16.9,48$ & $1.5,1.9$ & & & & & $24 \mathrm{~h} / 100^{\circ} \mathrm{C} /$ cap off & 1 & $\gamma$ \\
\hline 9 & 356 & 1.9 & $17.3,47.9$ & $1.4,1.7$ & & & & & $24 \mathrm{~h} / 100^{\circ} \mathrm{C} /$ cap off & 10 & $\gamma$ \\
\hline 9 & 431 & 2.359 & $16.6,47.1$ & $1.4,1.6$ & & & & & $24 \mathrm{~h} / 25^{\circ} \mathrm{C} / \mathrm{cap}$ off & 1 & $\gamma$ \\
\hline 9 & 431 & 2.196 & $15.9,44.7$ & $1.4,1.3$ & & & & & $24 \mathrm{~h} / 25^{\circ} \mathrm{C} / \mathrm{cap}$ off & 10 & $\gamma$ \\
\hline 10 & 421 & 2.936 & $20,47.8$ & $1.7,1.5$ & \multirow{6}{*}{$\mathrm{H}$} & \multirow{6}{*}{$\mathrm{N}$} & \multirow{6}{*}{$\mathrm{H}$} & \multirow{6}{*}{$\mathrm{Y}$} & $24 \mathrm{~h} / 100^{\circ} \mathrm{C} /$ cap off & 1 & $\gamma+$ trace? \\
\hline 10 & 397 & 2.968 & $21.2,49.7$ & $1.8,1.4$ & & & & & $24 \mathrm{~h} / 100^{\circ} \mathrm{C} /$ cap off & 10 & $\gamma+$ trace? \\
\hline 10 & 280 & 1.658 & 36.4 & 1.6 & & & & & $24 \mathrm{~h} / 25^{\circ} \mathrm{C} / \mathrm{cap}$ on & 1 & $\gamma+$ trace? \\
\hline 10 & 258 & 1.762 & 34.8 & 1.6 & & & & & $24 \mathrm{~h} / 25^{\circ} \mathrm{C} /$ cap on & 10 & $\gamma+$ trace? \\
\hline 10 & 247 & 1.52 & 34.9 & 1.6 & & & & & $24 \mathrm{~h} / 25^{\circ} \mathrm{C} / \mathrm{cap}$ off & 1 & $\gamma+$ trace? \\
\hline 10 & 220 & 1.508 & 35.9 & 1.6 & & & & & $24 \mathrm{~h} / 25^{\circ} \mathrm{C} / \mathrm{cap}$ off & 10 & $\gamma+$ trace? \\
\hline 11 & 234 & 1.476 & $26.7,59.7$ & $2.1,1.3$ & \multirow{6}{*}{$\mathrm{H}$} & \multirow{6}{*}{$\mathrm{Y}$} & \multirow{6}{*}{$\mathrm{H}$} & \multirow{6}{*}{$\mathrm{Y}$} & $\mathrm{N}$ & 1 & $\gamma+\operatorname{trace} \alpha$ \\
\hline 11 & 189 & 1.393 & 38.3 & 1.6 & & & & & $\mathrm{~N}$ & 10 & $\gamma+\alpha$ \\
\hline 11 & 239 & 1.519 & $25.3,56.3$ & $2.0,1.3$ & & & & & $24 \mathrm{~h} / 25^{\circ} \mathrm{C} /$ cap on & 1 & $\gamma+\operatorname{trace} \alpha$ \\
\hline 11 & 236 & 1.588 & $25,58.9$ & $2.2,1.4$ & & & & & $24 \mathrm{~h} / 25^{\circ} \mathrm{C} /$ cap on & 10 & $\gamma+\operatorname{trace} \alpha$ \\
\hline 11 & 397 & 2.77 & $21,49.8$ & $1.7,1.4$ & & & & & $24 \mathrm{~h} / 100^{\circ} \mathrm{C} /$ cap off & 1 & $\gamma+$ trace? \\
\hline 11 & 366 & 2.75 & $19.3,48.3$ & $1.6,1.6$ & & & & & $24 \mathrm{~h} / 100^{\circ} \mathrm{C} /$ cap off & 10 & $\gamma+$ trace? \\
\hline 12 & 323 & 1.634 & 17.0 & 1.2 & \multirow{6}{*}{ M } & \multirow{6}{*}{$\mathrm{N}$} & \multirow{6}{*}{$\mathrm{H}$} & \multirow{6}{*}{$\mathrm{N}$} & $24 \mathrm{~h} / 25^{\circ} \mathrm{C} /$ cap on & 1 & $\gamma$ \\
\hline 12 & 366 & 1.899 & 17.4 & 1.2 & & & & & $24 \mathrm{~h} / 25^{\circ} \mathrm{C} / \mathrm{cap}$ on & 10 & $\gamma$ \\
\hline 12 & 323 & 1.533 & 17.5 & 1.2 & & & & & $24 \mathrm{~h} / 25^{\circ} \mathrm{C} /$ cap off & 1 & $\gamma+$ trace? \\
\hline 12 & 362 & 1.657 & 17.5 & 1.2 & & & & & $24 \mathrm{~h} / 25^{\circ} \mathrm{C} / \mathrm{cap}$ off & 10 & $\gamma+$ trace? \\
\hline 12 & 368 & 2.074 & 17.7 & 1.2 & & & & & $24 \mathrm{~h} / 100^{\circ} \mathrm{C} /$ cap off & 1 & $\gamma$ \\
\hline 12 & 390 & 2.042 & 18.2 & 1.2 & & & & & $24 \mathrm{~h} / 100^{\circ} \mathrm{C} /$ cap off & 10 & $\gamma$ \\
\hline 13 & 257 & 1.427 & 40.4 & 1.6 & \multirow{6}{*}{ M } & \multirow{6}{*}{$\mathrm{N}$} & \multirow{6}{*}{$\mathrm{H}$} & & $\mathrm{N}$ & 1 & $\gamma$ \\
\hline 13 & 213 & 1.172 & 44.8 & 1.5 & & & & & $\mathrm{~N}$ & 10 & $\gamma$ \\
\hline 13 & 288 & 1.385 & 41.7 & 1.7 & & & & & $24 \mathrm{~h} / 25^{\circ} \mathrm{C} /$ cap on & 1 & $\gamma$ \\
\hline 13 & 272 & 1.43 & 41.1 & 1.7 & & & & $Y$ & $24 \mathrm{~h} / 25^{\circ} \mathrm{C} /$ cap on & 10 & $\gamma$ \\
\hline 13 & 252 & 1.421 & 41.1 & 1.6 & & & & & $24 \mathrm{~h} / 25^{\circ} \mathrm{C} /$ cap off & 1 & $\gamma+$ trace? \\
\hline 13 & 266 & 1.592 & 41.5 & 1.7 & & & & & $24 \mathrm{~h} / 25^{\circ} \mathrm{C} /$ cap off & 10 & $\gamma+$ trace? \\
\hline 14 & 327 & 1.737 & 18.2 & 1.3 & & & & & $\mathrm{~N}$ & 1 & $\gamma$ \\
\hline 14 & 360 & 1.608 & 17.3 & 1.3 & & & & & $\mathrm{~N}$ & 10 & $\gamma+$ trace? \\
\hline 14 & 361 & 1.639 & 16.5 & 1.3 & & & & & $24 \mathrm{~h} / 25^{\circ} \mathrm{C} / \mathrm{cap}$ off & 1 & $\gamma+$ trace? \\
\hline 14 & 338 & 1.725 & 17.6 & 1.2 & $\mathrm{H}$ & $\mathrm{N}$ & $\mathrm{H}$ & $\mathrm{N}$ & $24 \mathrm{~h} / 25^{\circ} \mathrm{C} / \mathrm{cap}$ off & 10 & $\gamma+$ trace? \\
\hline 14 & 345 & 1.811 & 17.1 & 1.2 & & & & & $24 \mathrm{~h} / 25^{\circ} \mathrm{C} /$ cap on & 1 & $\gamma+$ trace? \\
\hline 14 & 410 & 1.832 & 15.6 & 1.3 & & & & & $24 \mathrm{~h} / 25^{\circ} \mathrm{C} /$ cap on & 10 & $\gamma+$ trace? \\
\hline 15 & 325 & 1.682 & $17,48.5$ & $1.6,1.5$ & & & & & $\mathrm{~N}$ & 1 & $\gamma+$ trace? \\
\hline 15 & 356 & 1.913 & $16.6,49.7$ & $1.9,1.5$ & & & & & $\mathrm{~N}$ & 10 & $\gamma+$ trace? \\
\hline 15 & 417 & 1.999 & $14.4,46.9$ & $1.8,1.5$ & & & & & $24 \mathrm{~h} / 100^{\circ} \mathrm{C} /$ cap off & 1 & $\gamma+$ trace? \\
\hline 15 & 358 & 1.765 & $13.6,44.7$ & $1.9,1.6$ & $\mathrm{M}$ & $\mathrm{Y}$ & $\mathrm{L}$ & $\mathrm{N}$ & $24 \mathrm{~h} / 100^{\circ} \mathrm{C} /$ cap off & 10 & $\gamma+$ trace? \\
\hline 15 & 350 & 1.738 & $15.4,45.2$ & $1.9,1.3$ & & & & & $24 \mathrm{~h} / 25^{\circ} \mathrm{C} /$ cap off & 1 & $\gamma+$ trace? \\
\hline 15 & 368 & 1.698 & $15.9,43.2$ & $1.8,1.2$ & & & & & $24 \mathrm{~h} / 25^{\circ} \mathrm{C} /$ cap off & 10 & $\gamma+$ trace? \\
\hline 16 & 232 & 1.583 & 39.9 & 1.7 & & & & & $\mathrm{~N}$ & 1 & $\gamma+$ trace? \\
\hline 16 & 236 & 1.429 & 45.1 & 1.6 & & & & & $\mathrm{~N}$ & 10 & $\gamma+$ trace? \\
\hline 16 & 248 & 1.496 & 34.7 & 1.6 & & & & & $24 \mathrm{~h} / 25^{\circ} \mathrm{C} / \mathrm{cap}$ off & 1 & $\gamma$ \\
\hline 16 & 227 & 1.57 & 36.4 & 1.6 & $\mathrm{H}$ & $\mathrm{N}$ & $\mathrm{L}$ & $\mathrm{Y}$ & $24 \mathrm{~h} / 25^{\circ} \mathrm{C} /$ cap off & 10 & $\gamma$ \\
\hline 16 & 424 & 2.763 & $18.3,45.9$ & $1.6,1.5$ & & & & & $24 \mathrm{~h} / 100^{\circ} \mathrm{C} /$ cap off & 1 & $\gamma$ \\
\hline 16 & 402 & 2.685 & $17.9,46.5$ & $1.5,1.6$ & & & & & $24 \mathrm{~h} / 100^{\circ} \mathrm{C} /$ cap off & 10 & $\gamma$ \\
\hline
\end{tabular}

a. Determined by $\mathrm{N}_{2}$ adsorption at $77 \mathrm{~K}$

b. Determined by improved slit pore geometry (SPG) model for large pore size using desorption branch

c. Determined using X-ray diffraction method 
Table 2. Trials to confirm the models and predictions

\begin{tabular}{|c|c|c|c|c|c|c|c|c|c|c|}
\hline $\begin{array}{c}\text { Mix } \\
\text { Method }\end{array}$ & Mix Seal & $\underset{\text { (min.) }}{\text { Mix Time }}$ & $\begin{array}{c}\text { Excess } \\
\text { Alcohol }\end{array}$ & $\begin{array}{l}\text { Drying } \\
\left(\mathrm{T} /{ }^{\circ} \mathrm{C}\right)\end{array}$ & $\begin{array}{c}\text { Pred. } \\
\text { Surface } \\
\text { Area } \\
\left(\mathrm{m}^{2} / \mathrm{g}\right) \\
\end{array}$ & $\begin{array}{c}\text { Pred. } \\
\text { Pore } \\
\text { Volume } \\
\left(\mathrm{cm}^{3} / \mathrm{g}\right) \\
\end{array}$ & $\begin{array}{c}\text { Pred. } \\
\text { Pore } \\
\text { Diameter } \\
(\mathbf{n m}) \\
\end{array}$ & $\begin{array}{c}\text { Actual } \\
\text { Surface } \\
\text { Area } \\
\left(\mathrm{m}^{2} / \mathrm{g}\right)^{\mathrm{a}}\end{array}$ & $\begin{array}{c}\text { Actual } \\
\text { Pore } \\
\text { Volume } \\
\left(\mathrm{cm}^{2} / \mathbf{g}\right)^{\mathrm{a}}\end{array}$ & $\begin{array}{l}\text { Actual } \\
\text { Pore } \\
\text { Diameter } \\
(\mathbf{n m})^{\mathbf{b}}\end{array}$ \\
\hline Hand & No & 30 & No & 100 & 368 & 1.87 & 17.2 & 282.2 & 1.5 & 18.01 \\
\hline Hand & Yes & 15 & No & 100 & 368 & 1.87 & 16.5 & 414.7 & 2.1 & 18.19 \\
\hline Machine & No & 30 & No & 100 & 388 & 1.71 & 17.8 & 375.4 & 1.9 & 46.7 \\
\hline Machine & No & 15 & No & 100 & 388 & 1.71 & 18.0 & 381.1 & 1.8 & 20.99 \\
\hline Hand & Yes & 30 & No & 100 & 368 & 1.87 & 47.3 & 340 & 2.5 & 48.7 \\
\hline Machine & No & 30 & Yes & 100 & 350 & 1.71 & 41.9 & 272.8 & 2 & 45 \\
\hline Machine & Yes & 30 & Yes & 100 & 350 & 1.71 & 58.4 & 371.7 & 2.4 & 47.9 \\
\hline
\end{tabular}

a. Determined by $\mathrm{N}_{2}$ adsorption at $77 \mathrm{~K}$

b. Determined by improved slit pore geometry (SPG) model for large pore size using desorption branch 


\section{Figure Captions:}

Figure 1. Representative $\mathrm{N}_{2}$ adsorption/desorption isotherms and corresponding pore size distributions of SDAs with bi-model pore size distribution.

Figure 2. Interaction of excess alcohol, drying method and mixing method on surface area.

Figure 3. Interaction of excess alcohol and calcination ramp on surface area.

Figure 4. Interaction between excess alcohol, mixing time, mixing seal and mixing method on pore diameter.

Figure 5. Average effect of drying method on pore volume.

Figure 6. Average effect of mixing method on pore volume.

Figure 7. TEM micrograph of SDA synthesized from second batch with no drying condition. 


\section{Figures}
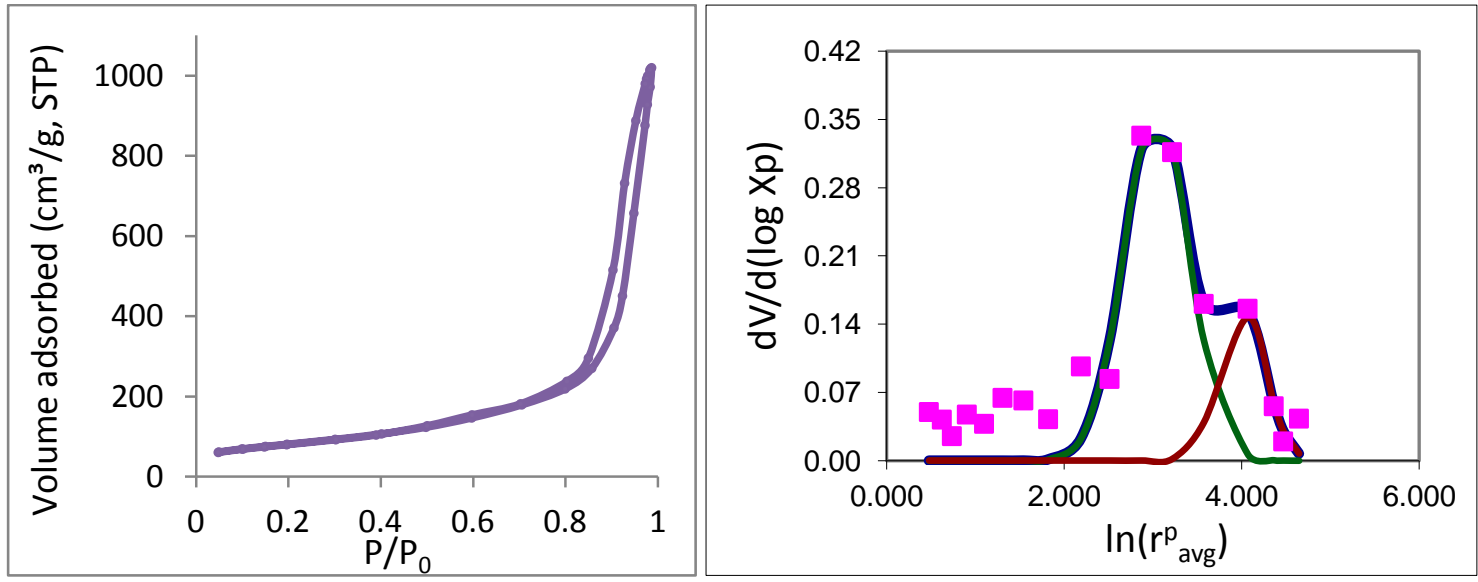

Figure 1. 


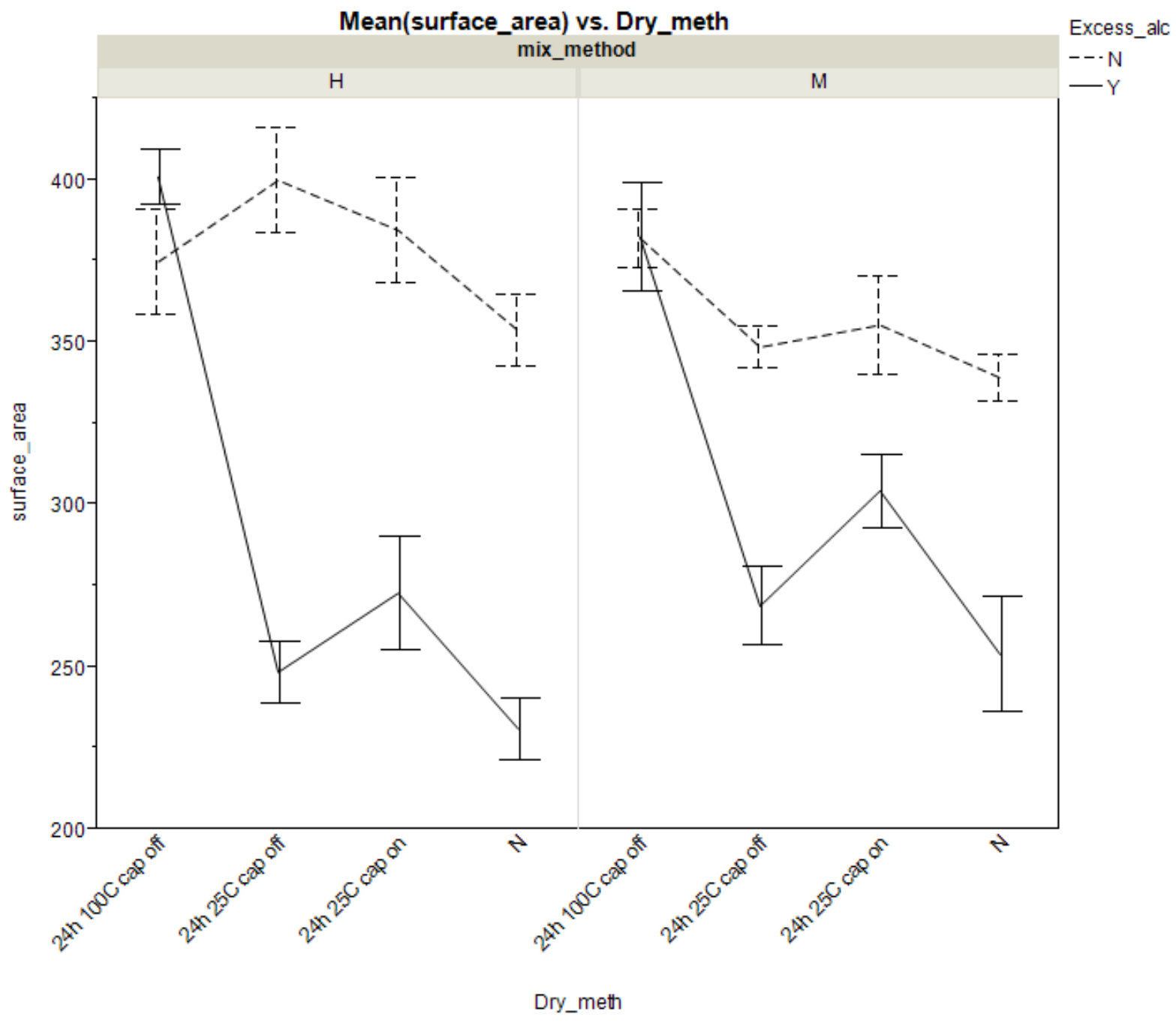

Mixing method: $\mathrm{H}$ (hand mix), M (machine)

Excess alcohol: N (No), Y (Yes)

Drying method: $24 \mathrm{~h} 100^{\circ} \mathrm{C}$ cap off $\left(24 \mathrm{~h}\right.$ drying at $100^{\circ} \mathrm{C}$ in unsealed mixing environment) Drying method: $24 \mathrm{~h} 25^{\circ} \mathrm{C}$ cap on $\left(24 \mathrm{~h}\right.$ drying at $25^{\circ} \mathrm{C}$ in sealed mixing environment $)$ Drying method: N (No)

Figure 2. 


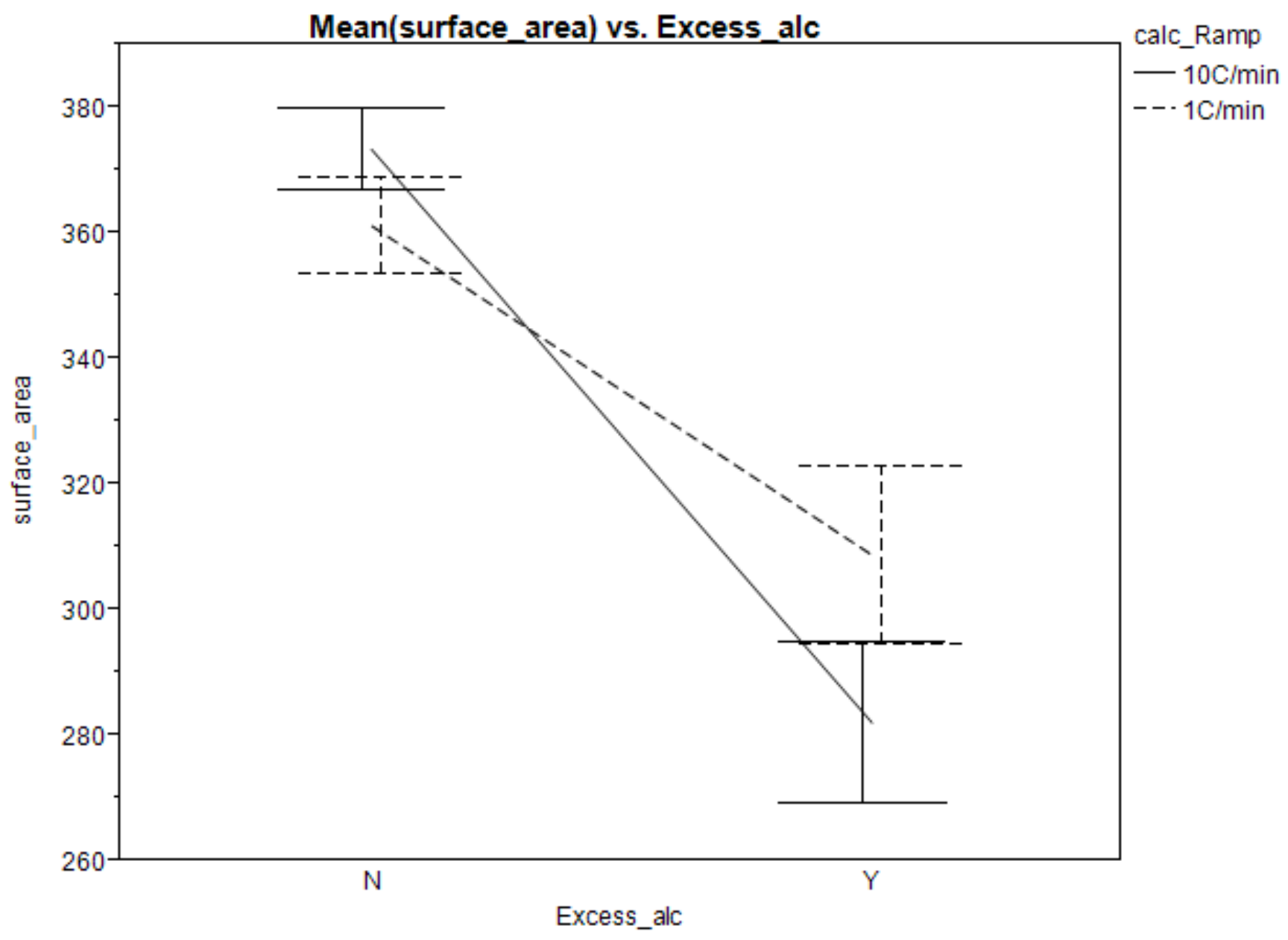

Excess alcohol: N (No), Y(Yes)

Calcinations ramp: $10^{\circ} \mathrm{C} / \mathrm{min}$ or $1^{\circ} \mathrm{C} / \mathrm{min}$

Figure 3. 


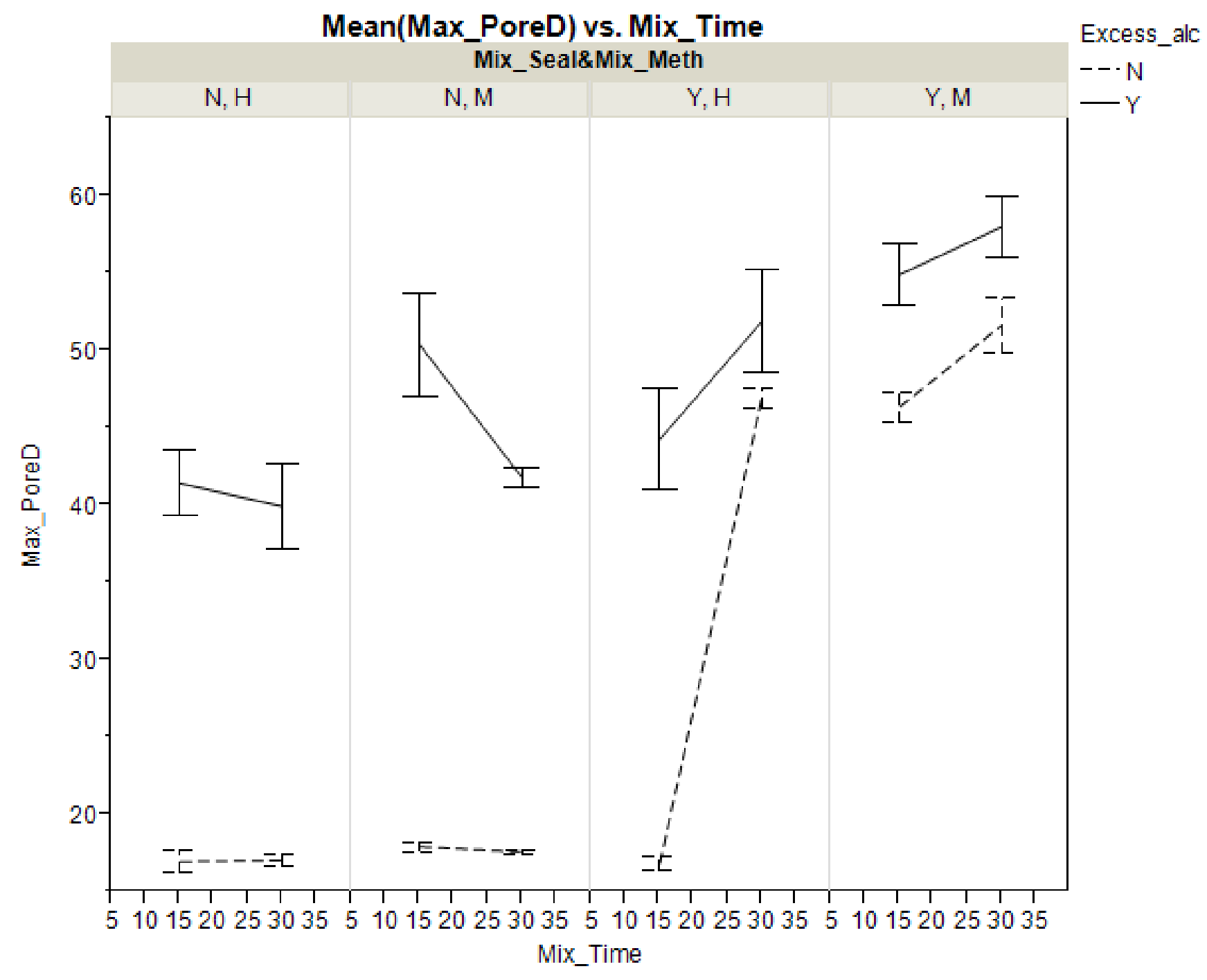

Mixing time: 15 or 30 minutes

Excess alcohol: N (No), Y (Yes)

Mixing seal: N (No), Y (Yes)

Mixing method: $\mathrm{H}$ (hand mix), M (machine)

Figure 4. 


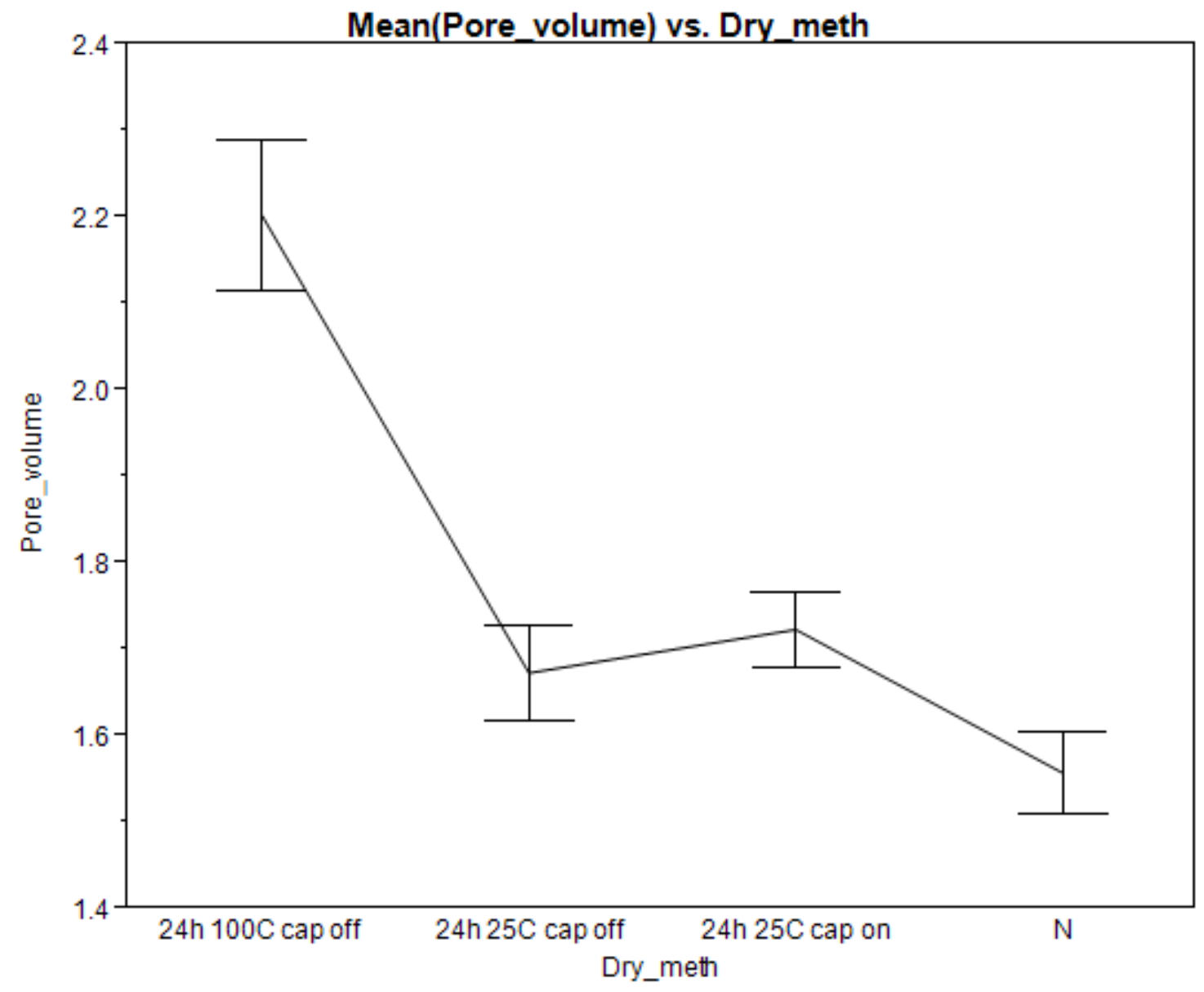

- Mean(Pore_volume)

Drying method: $24 \mathrm{~h} 100^{\circ} \mathrm{C}$ cap off $\left(24 \mathrm{~h}\right.$ drying at $100^{\circ} \mathrm{C}$ in unsealed mixing environment) Drying method: $24 \mathrm{~h} 25^{\circ} \mathrm{C}$ cap on $\left(24 \mathrm{~h}\right.$ drying at $25^{\circ} \mathrm{C}$ in sealed mixing environment $)$ Drying method: N (No)

Figure 5. 


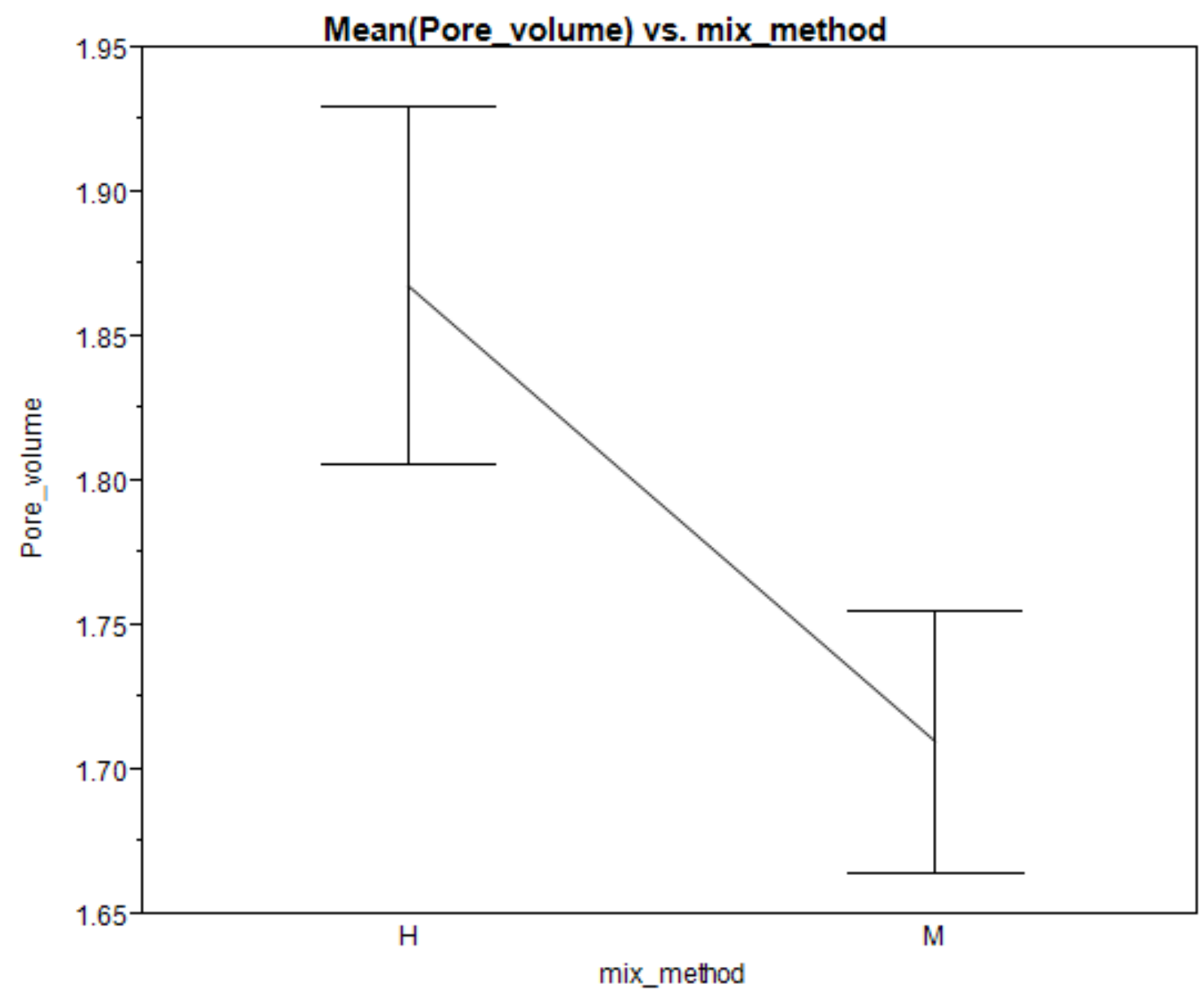

_ Mean(Pore_volume)

Mixing method: $\mathrm{H}($ hand mix), $\mathrm{M}$ (machine)

Figure 6. 


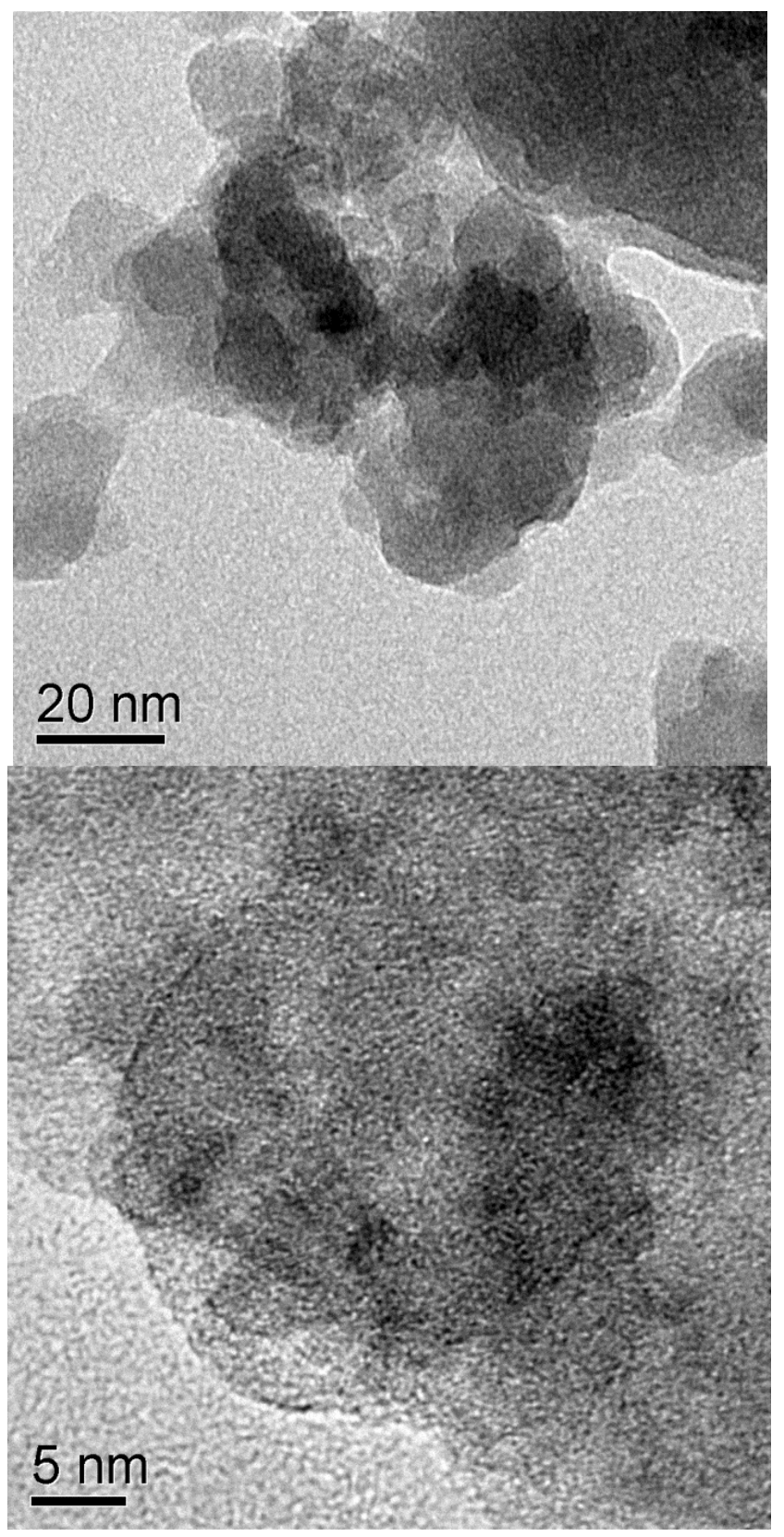

Figure 7. 


\begin{tabular}{|c|c|c|c|}
\hline Hydrolysis step & Drying step & & \\
\hline$\frac{\text { Mixing time: }}{30 \mathrm{~min} \text { or } 15 \mathrm{~min}}$ & $\begin{array}{l}\text { Drying: } \\
\text { No or Yes }\end{array}$ & & Results \\
\hline Mixing method: & Time: & Calcination step & 1. Thermally stable $\gamma$-alumina \\
\hline Hand or Machine & $24 \mathrm{~h}$ & Calcination ramp: & catalyst support. \\
\hline Mixing sealing: & Temperature: & $10^{\circ} \mathrm{C} / \mathrm{min}$ or $1^{\circ} \mathrm{C} / \mathrm{min}$ & $\begin{array}{l}\text { 2. Control porosity from } 14 \text { to } \\
60 \mathrm{~nm} \text { while having large }\end{array}$ \\
\hline Sealed or Not sealed & $25^{\circ} \mathrm{C}$ or $100^{\circ} \mathrm{C}$ & & pore volumes and high \\
\hline Using excess alcohol: & Sealing: & & \\
\hline
\end{tabular}

